\title{
Pengembangan Sistem Inventory Alat Tulis Kantor (ATK) Berbasis Web
}

\author{
Rusydi Umar' ${ }^{1}$ Novita Ranti Muntiari' ${ }^{2}$ Ermin $^{3}$, Iqbal Bustomi ${ }^{4}$, Fitriyani Tella ${ }^{5}$ \\ 1,2,3,4,5Magister Teknik Informatika, Universitas Ahmad Dahlan \\ Jl. Prof Jl. Prof. Dr. Soepomo, S.H, Warungboto, Yogyakarta 55164 \\ 11rusydi_umar@rocketmail.com, 2novita1907048010@webmail.uad.ac.id, \\ 3erminhimatif3771@gmail.com, 4iqbal190704801@webmail.uad.ac.id, \\ 5fitriyanitella13@gmail.com
}

\begin{abstract}
Developments in the technological era are increasingly developing and people's needs vary with the desire to accelerate a job in a systematic and more effective and efficient manner. The problems faced by PT. XYZ in supplies of office equipment are still poorly organized and there is no reporting on the use of office stationery (ATK) and inhibitors of employee productivity because there is no precise inventory information and delays in making reports. Facilitates the company in the process of inventory input Application of the method in this research is to use the classic life cycle (CLC) method, known as the process design, which is carried out sequentially, with the research stages beginning with analysis, design, coding and testing.From the several stages that have been carried out in this researcher can produce reports stock of goods and office stationery information updated to users or visitors.
\end{abstract}

Keywords: CLC, inventory, ATK

\section{Abstrak}

Perkembangan di era teknologi semakin berkembang dan kebutuhan orang berbeda- beda dengan keinginan mempercepat suatu pekerjaan dengan sistematis dan lebih efektif dan efesiensi. Permasalahan yang di hadapi oleh PT.XYZ persediaan alat kantor masih kurang terorganisir dan belum ada pelaporan penggunaan alat tulis kantor (ATK) dan penghambat produktifitas kerja karyawan karena tidak ada informasi persediaan barang secara tepat dan keterlambatan membuat laporan. Memudahkan pihak perusahaan dalam proses persediaan barang masukan maupun keluar. Penerapan metode dalam penilitian ini adalah menggunakan metode classic life cycle (CLC) yang dikenal dengan desain prosesnya dilakukan secara berurutan, dengan tahapan penelitian diawali analisis, desain, pengkodean dan pengujian. Dari beberapa tahapan yang telah dilakukan dalam peneliti ini dapat menghasilkan laporan stok barang dan informasi alat tulis kantor terupdate ke pengguna atau pengunjung.

Kata Kunci : CLC, Inventory, ATK

\section{PENDAHULUAN}

Teknologi yang semakin berkembang dengan kebutuhan yang dituntut untuk sistematis dan cara kerja yang dirubah dengan lebih efektif dan efesien, perlu diciptakan sistem yang membatu sistem kerja lebih cepat [1]. Pemanfaatan database dalam suatu pekerjaan dengan sistematis sangat dibutuhkan di era saat ini. Database sebuah tempat penyimpanan yang berisi data berupa operasional data dan juga deskripsi data. Kumpulan data tersebut yang dibutuhkan oleh sebuah organisasi yang dirancang untuk menemukan informasi [2],[3],[4]. Saat ini masalah yang dihadapi oleh PT.XYZ dalam persediaan alat kantor masih kurang terorganisir dan belum ada pelaporan penggunaan ATK. Dengan adanya sistem ini permasalahan yang 
sebelumnya kurang terorganisir, tidak ada informasi persediaan barang secara tepat, keterlambatanya dalam membuat laporan dapat teratasi.

Untuk selanjutnya mengatasi masalah yang ada, menerapkan sebuah sistem penyajian informasi persediaan alat tulis kantor menggunakan metode classic life cycle (CLC), dimana informasi tentang persediaan alat tulis kantor dapat diakses secara langsung dan pada saat waktu dibutuhkan, Bagian pengelola yang akan menyediakan fasilitas sistem persediaan alat tulis kantor yang dibutuhkan. Dengan adanya sistem ini dapat membantu mengoptimalkan pekerjaan yang sudah berjalan sebelumnya dengan lebih sistematis dan terorganisir dengan membangun sistem inventory ATK berbasis WEB di PT. XYZ.

\section{METODOLOGI PENELITIAN}

Dalam penelitian ini menggunakan metode CLC . CLC adalah suatu metode sistem yang bekerja secara sistematik, metode ini bekerja mulai dari satu level sistem, kemudian maju ke level berikutnya. Tahapan dari metode CLC dapat ditunjukkan pada Gambar 1 [5],[6],[7].

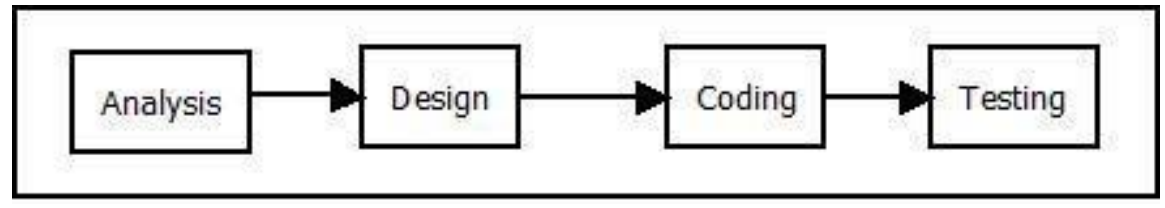

Gambar 1. Tahapan metode CLC inventory ATK

Tahapan metode CLC dalam penerapan di sistem inventory ATK yang ditunjukkan di Gambar 1 dijelaskan sebagai berikut :

a) Analysis

Menganalisa dan mengumpulkan kebutuhan yang akan di bangun dan data yang dibutuhkan dipenelitian ini termasuk data user, katagory dan data barang.

b) Design

Membuat rancangan input dan output dengan menggunakan ERD dan DFD dan mapping table yang digunakan di sistem yang selanjutnya akan di implementasikan.

c) Coding

Mengimplementasikan dari rancangan sistem ke suatu bentuk program dengan mengkonversi hasil rancangan menjadi source code.

d) Testing

Dilakukan testing atau pengujian terhadap sistem inventory ATK mengetahui sistem berjalan sesuai dengan harapan atau belum dan pengujian berfungsi mengetahui ada kesalahan atau tidak pada sistem yang dibuat. 
Analisa kebutuhan dimana proses agar dapat dipahami oleh user. Sistem memerlukan sebagai berikut[8]:

a. Sistem memperlihatkan halaman login untuk admin.

b. Sistem memperlihatkan halaman dashboard ketika berhasil login.

c. Sistem menginput data barang, data kategori, data user.

d. Sistem dapat mengolah data barang masuk dan data barang keluar.

e. Sistem dapat mengirimkan informasi barang ke pengunjung.

f. Sistem dapat membuat laporan per minggu dan perbulan stok barang yang akan di berikan oleh admin.

Perancangan sistem dalam membangun sistem inventory alat tulis kantor (ATK) berbasis web ini dibutuhkan beberapa rancangan, rancangan yang digunakan untuk membangun penelitian ini adalah Data Flow Diagram (DFD) sampai level 1 dan gambaran menggunakan Entity Relationship Diagram (ERD) dan Rancangan Entity Relationship Diagram (ERD) dapat ditunjukkan pada Gambar 2 [5],[9],[10].

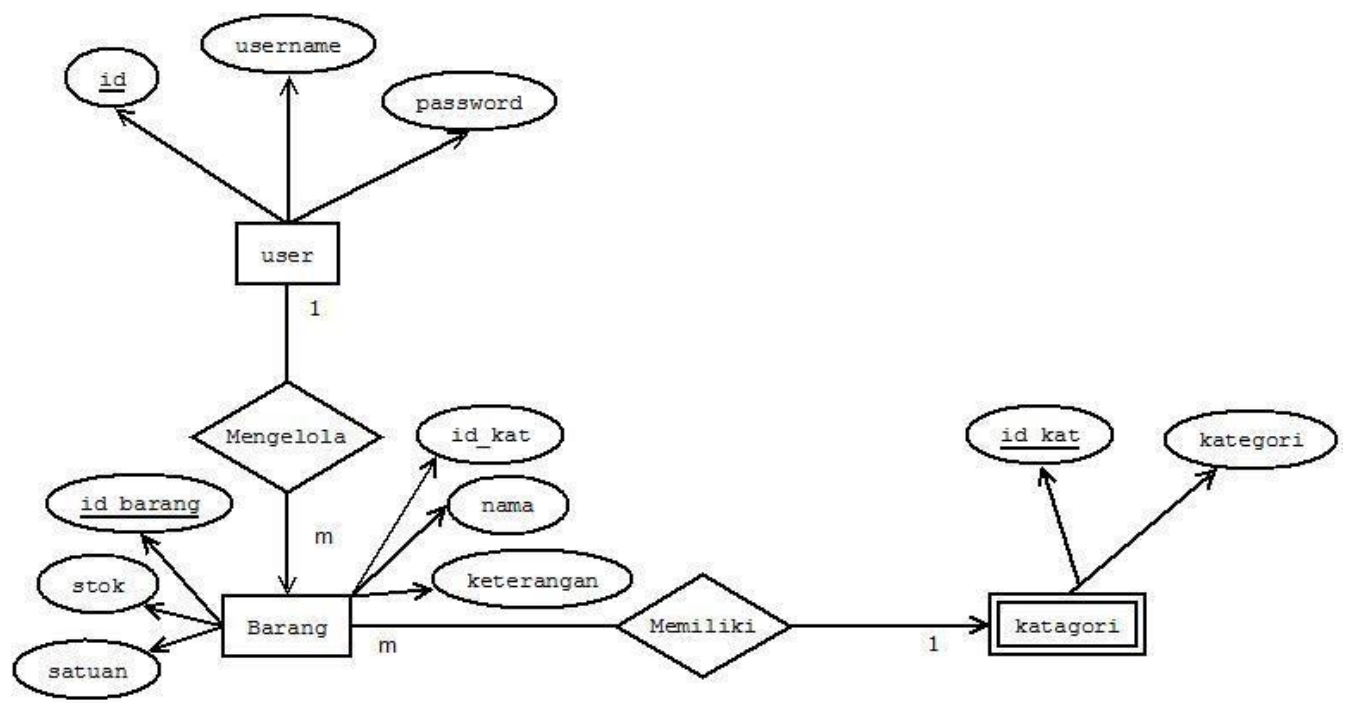

Gambar 2. ERD inventory ATK

Mapping table dengan 3 tabel yaitu user, barang, dan ketagori. Tabel barang berelasi dengan tabel kategori dimana one to many, dengan mapping table dapat ditunjukkan pada Gambar 3.

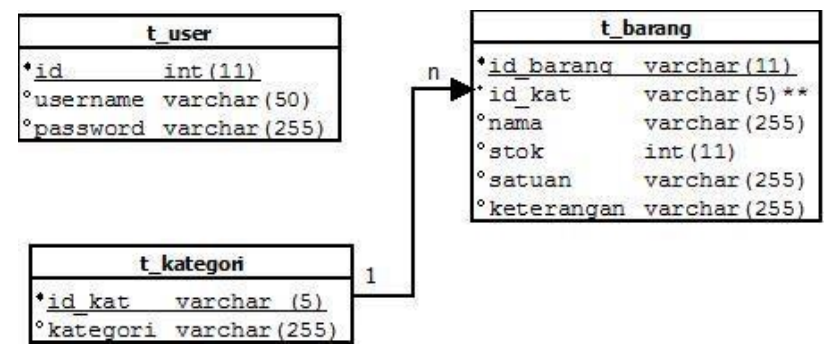

Gambar 3. Mapping table inventory ATK 
DFD dengan berupa DFD level 0 dan data DFD level 1. Data DFD level 0 dengan 2 entitas dari hasil proses entitas tamu atau pengunjung mendapatkan informasi barang sedangkan entitas admin menginputkan data barang, data user dan data kategori dan mendapatkan dari hasil proses daftar barang, daftar user, daftar kategori dan laporan stok barang. DFD level 0 dapat ditunjukkan di Gambar 4.

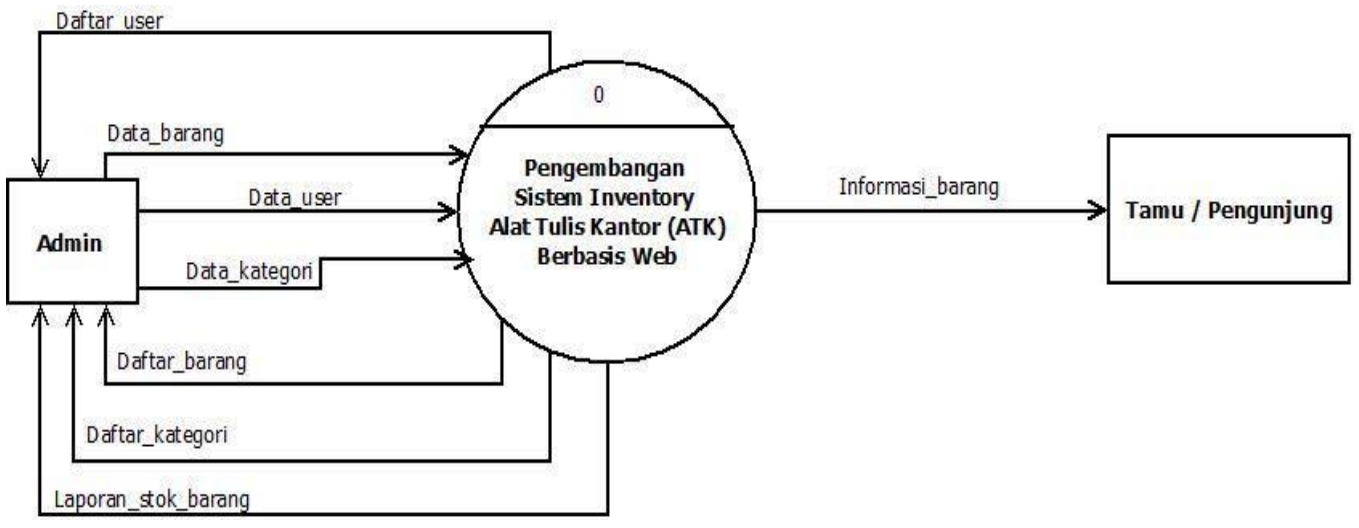

Gambar 4. DFD level 0 inventory ATK

DFD level 0 menghasilkan DFD level 12 entitas dari hasil proses entitas tamu atau pengunjung mendapatkan informasi barang sedangkan entitas admin menginputkan data barang, data user dan data kategori dan mendapatkan dari hasil proses daftar barang, daftar user, daftar kategori dan disimpan ke database dengan nama tabel user, tabel barang, dan tabel kategori dengan menghasilkan laporan stok barang yang di proses dari tabel barang dan kategori barang dengan laporan per minggu dan perbulan yang akan diterima oleh admin. DFD level 0 dapat ditunjukkan di Gambar 5.

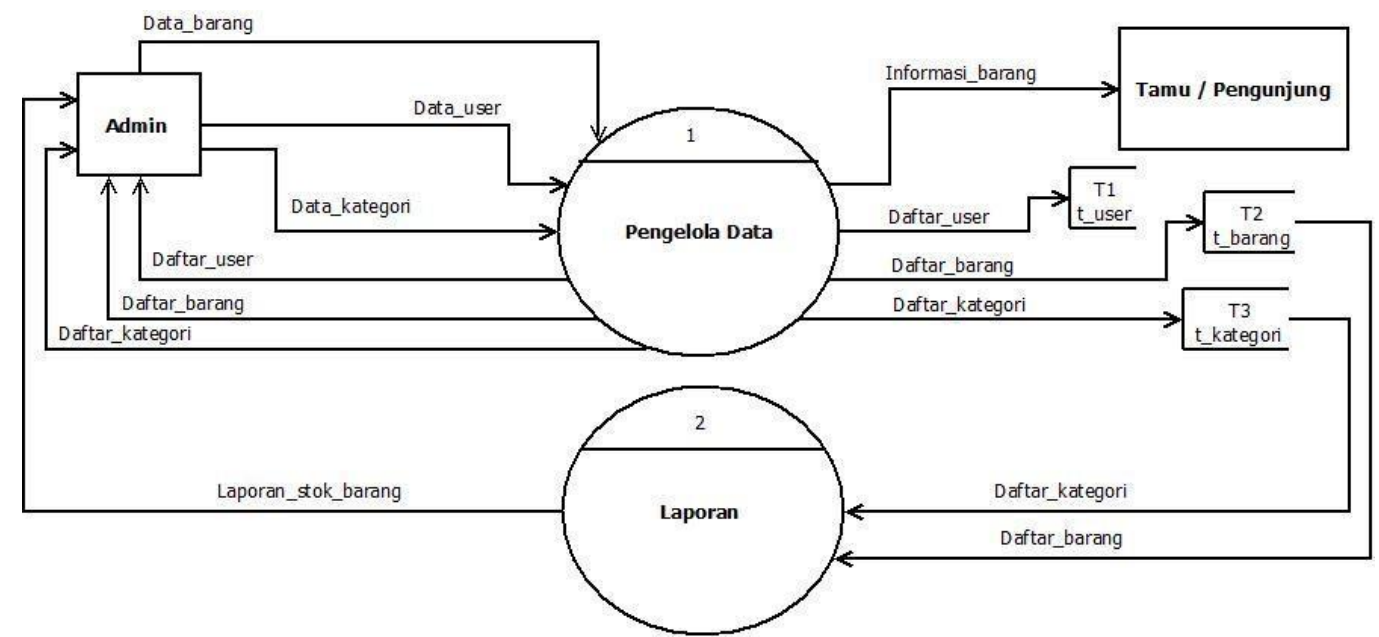

Gambar 5. DFD level 1 inventory ATK 


\section{HASIL DAN PEMBAHASAN}

Implementasi dari pembuatan database Salah satu dari strutur tabel MySQL, terdapat 3 struktur yang ditunjukkan di Tabel 1-3..

Tabel 1. Struktur user

\begin{tabular}{|c|c|c|}
\hline Nama field & Keterangan & Tipe data \\
\hline Id & ID user & Int [11] \\
\hline username & Username user & Varchar [50] \\
\hline password & Password user & Varchar [255] \\
\hline
\end{tabular}

Tabel 2. Struktur barang

\begin{tabular}{|c|c|c|}
\hline Nama field & Keterangan & Tipe data \\
\hline Id_barang & ID barang & Varchar [11] \\
\hline nama & Nama barang & Varchar [255] \\
\hline Stok & Stok barang & Int [11] \\
\hline Satuan & Satuan barang & Varchar [255] \\
\hline Keterangan & Keterangan barang & Varchar [255] \\
\hline Id_kat & Id kategori & Varchar [5] \\
\hline
\end{tabular}

Tabel 3. Struktur Kategori

\begin{tabular}{|c|c|c|}
\hline Nama field & Keterangan & Tipe data \\
\hline Id_kat & ID kategori & Varchar [5] \\
\hline kategori & Nama Kategori & Varchar [255] \\
\hline
\end{tabular}

Beberapa fungsi perintah atau script SQL yaitu membuat tabel (create), mengubah tabel (alter) dan menghapus tabel (drop). DDL adalah kumpulan beberapa perintah SQL untuk memvisualkan desain database secara menyeluruh [3], berikut script DDL yang diimplementasikan pada inventori alat tulis kantor (ATK) :

a) Script SQL membuat table user (create)

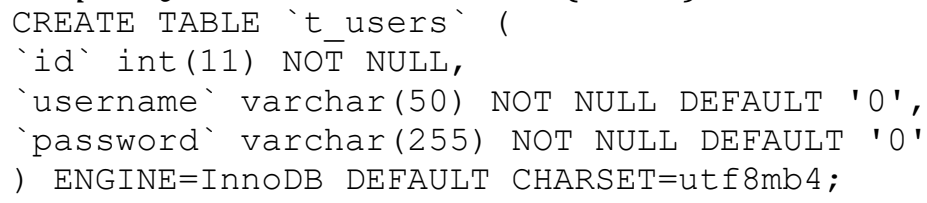

b) Script SQL membuat table kategori (create)

CREATE TABLE 't_kategori' (

'id_kat' varchār(5) NOT NULL,

'kategori' varchar(255) NOT NULL

) $\mathrm{ENGINE}=$ InnoDB DEFAULT CHARSET=utf8mb4;

c) Script SQL membuat table barang (create)

CREATE TABLE 't barang' (

'id_barang' varchar(11) NOT NULL,

'nama' varchar(255) NOT NULL,

'stok' int(11) NOT NULL, 


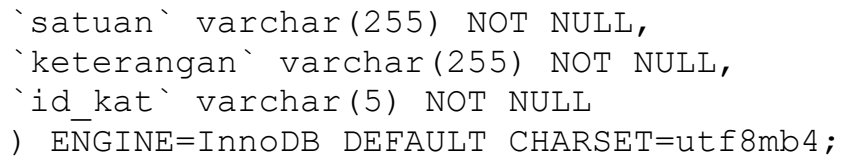

Pada penelitian ini hasil dan pembahasan dari sistem inventori alat tulis kantor (ATK) dengan penggunaan website dengan tampilan user pengguna yang mepermudah user dalam menggunakanya. Tampilan website dan menu-menu yang terdapat di dalam website dan hak akses yang diperoleh penggguna.

\section{a) Login}

Proses input hak akses oleh admin, yang terdiri dari username dan password. Tampilan login dapat ditunjukkan di Gambar 6.

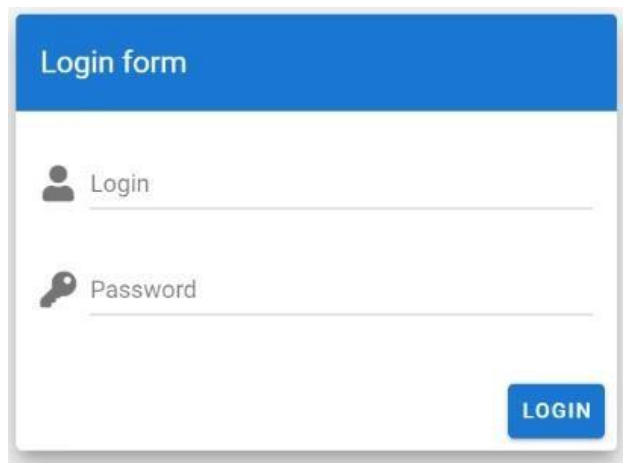

Gambar 6. Login hak akses admin

b) Search data barang

Proses pencarian data barang hak akses oleh pengguna/pengunjung. Tampilan search dapat ditunjukkan di Gambar 7.

\section{(9) SINTORY}

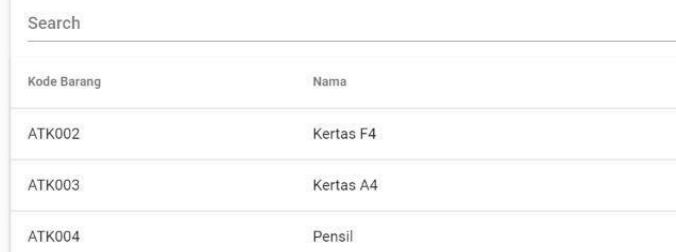

Q

Gambar 7. Search data barang

c) Input data pengguna atau user

Proses input data hak akses oleh admin, tampilan input data pengguna atau user dapat dilihat di Gambar 8. 


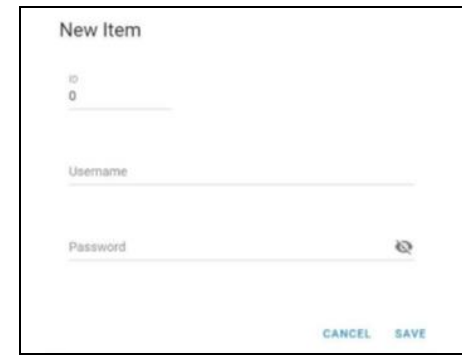

Gambar 8. Input data pengguna atau user

d) Data pengguna atau user

Proses input data user hak akses oleh admin, yang terdiri dari username dan password. Tampilan data pengguna atau user dapat ditunjukan Gambar 9.

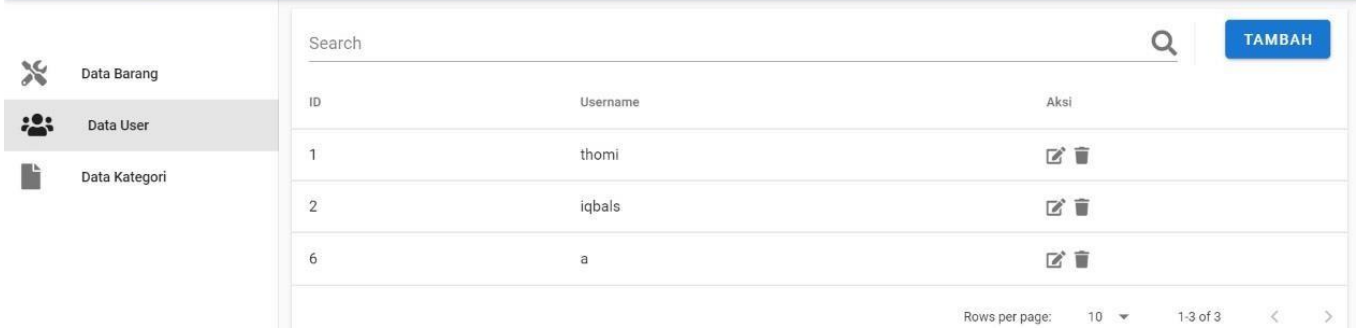

Gambar 9. Data pengguna atau user

e) Data kategori

Proses input data user hak akses oleh admin, yang terdiri dari nama kategori. Tampilan data kategori dapat ditunjukkan di Gambar 10.

\section{(9) SINTORY}

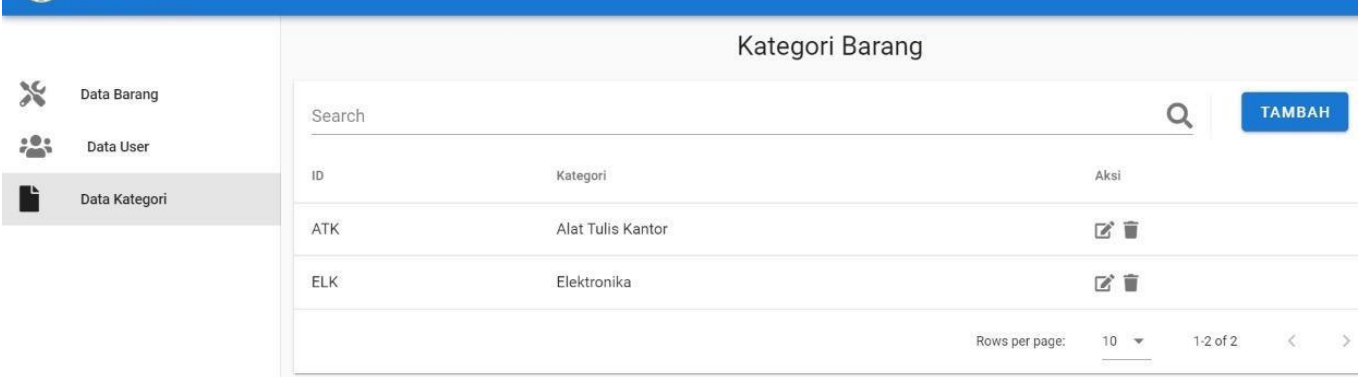

Gambar 10. Data Kategori

f) Input data kategori

Proses input data hak akses oleh admin, tampilan input data kategori dapat ditunjukkan di Gambar 11. 
g) Data barang

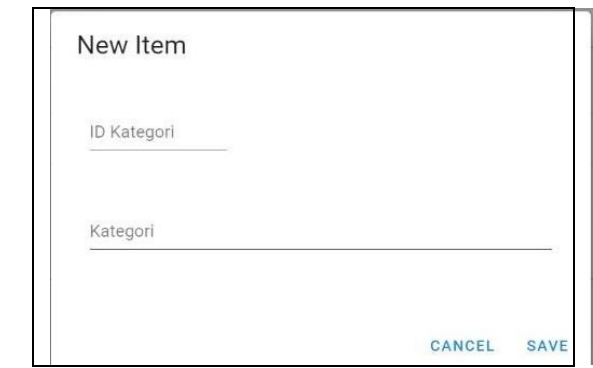

Gambar 11. Input Data Kategori

Proses input dan edit data user hak akses oleh admin, yang terdiri dari nama barang, stok, satuan dan keterangan. Tampilan data barang dapat ditunjukkan di Gambar 12.

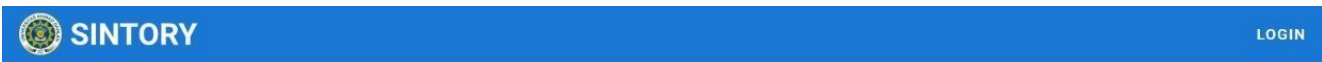

\begin{tabular}{|c|c|c|c|c|c|c|c|c|}
\hline \multirow{2}{*}{\multicolumn{2}{|c|}{ Xf Data Barang }} & \multicolumn{4}{|l|}{ Search } & $Q$ & LAPORAN & ТАМВАH \\
\hline & & Kode Barang & Nama & stok & Satuan & Keterenoner & Semua Barang & et \\
\hline \multirow{9}{*}{ : } & Data User & ATK001 & pulpen & 0 & box & & Barang Tersedia & in \\
\hline & Data Kategori & ATK002 & Kertas F4 & 100 & Karton & Tersedia & Stok Habis & [ \\
\hline & & ATK003 & Kertas A4 & 100 & Karton & Tersedia & & [ \\
\hline & & ATK004 & Pensil & 50 & Karton & Tersedia & & [6 \\
\hline & & ATK005 & Note & 100 & Biji & Tersedia & & Eீ \\
\hline & & ATK006 & Paperclip & 90 & Karton & Tersedia & & [ீ: \\
\hline & & ATK007 & Stabilo & 80 & Karton & Tersedia & & [C \\
\hline & & ATK008 & Spidol Kecil & 100 & Box & Tersedia & & Eே \\
\hline & & ATK009 & Spidol Marker & 100 & Karton & Tersedia & & [6 \\
\hline
\end{tabular}

h) Laporan Stok

Gambar 12. Data barang

Output laporan per bulan dan per minggu yang diberikan ke admin. Tampilan laporan dapat ditunjukkan di Gambar 13.

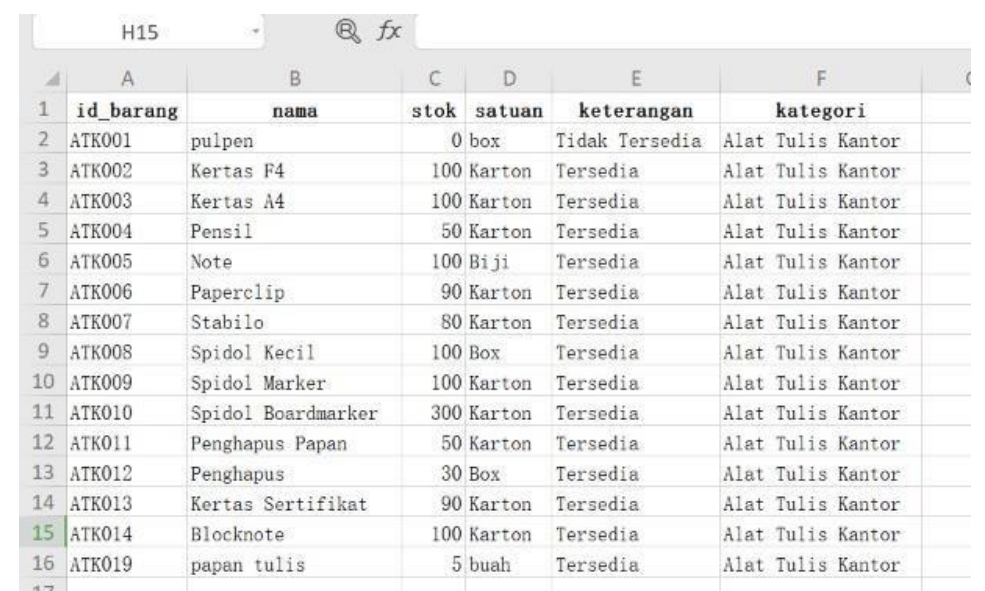

Gambar 13. Laporan Stok 


\section{SIMPULAN}

Membangun sistem untuk membantu dalam mengelola alat tulis kantor (ATK) lebih terkomputerisasi dan lebih mempermudah pengunjung atau pengguna mengetahui alat tulis kantor yang ada dan tidak ada di PT. XYZ. Penulis merangkum sebagai berikut :

a) Pemanfaatan dan penggunaan sistem Inventory ATK mempermudah admin admin dalam mengelolah inventory kantor.

b) Sistem inventory ATK membuat sistem kerja tidak manual.

c) Aplikasi mempermudah staff atau pengunjung untuk mengakses atau mengetahui data barang ATK ketika dibutuhkan.

d) Dengan menghasilkan laporan stok barang dan informasi alat tulis kantor terupdate ke pengguna atau pengunjung dan lebih bisa mengontrol stok yang keluar dan masuk.

\section{DAFTAR PUSTAKA}

[1] M. F. PAHLAWAN, "Sistem Informasi Persediaan Barang Alat Tulis Kantor (ATK) Berbasis Desktop pada Rsud Kota Bogor".

[2] A. Mulyani, O. Pahlevi, and M. Khoir, "Sistem Informasi Inventori Barang Menggunakan Metode Object Oriented Di Pt. Livaza Teknologi Indonesia Jakarta," J. PROSISKO, vol. 5, no. 1, 2018.

[3] R. Umar, A. Hadi, P. Widiandana, and F. Anwar, "Perancangan Database Point of Sales Apotek Dengan Menerapkan Model Data Relasional," vol. 5341, no. October, pp. 33-41, 2019.

[4] A. Prayudi, R. Umar, and A. Yudhana, "Perancangan Sistem Informasi Pariwisata Di Kabupaten Dompu Berbasis Website," Semin. Nas. Inform., vol. 2018, no. semnasIF, pp. 26-30, 2018.

[5] K. Jajang, "Perangkat Lunak untuk Mentransformasikan Model Entity Relationship ke Model Relational," Jurnal Pendidikan Teknolologi Informasi dan Komunikasi, vol. 2, no. 2, pp. 16-24, 2009.

[6] Evayani and U. Ulfah, "Perancangan Database Sistem Informasi Akuntansi Siklus Penjualan dengan Menggunakan Model REA (Studi Kasus pada PT Yudi Putra, Medan)," J. Ilm. Mhs. Ekon. Akunt., vol. 1, no. 2, pp. 16-29, 2016.

[7] K. Indriani, Sudarmadi, "Sistem Informasi Inventory Alat Tulis Kantor (Atk) Menggunakan Metode Waterfall (Studi Kasus : Otoritas Jasa Keuangan (OJK))", vol. 12, no. 1, pp. 69-76, 2015.

[8] G. W. Sasmito, "Penerapan Metode Waterfall Pada Desain Sistem Informasi Geografis Industri Kabupaten Tegal," Jurnal Informasi Pengembangan IT, vol. 2, no. 1, pp. 6-12, 2017.

[9] A. Prayudi, A. Yudhana, and R. Umar, "Implementasi Google Maps Pada Sistem Informasi Pariwisata Kabupaten Dompu Menggunakan Model Software Development Life Cycle (SDLC)," J. Mob. Forensics, vol. 1, no. 2, pp. 11-21, 2019.

[10] M. Tabrani and P. Eni, "Penerapan Metode Waterfall Pada Sistem Informasi Inventori Pt. Pangan Sehat Sejahtera," J. Inkofar, vol. 1, no. 2, pp. 30-40, 2017. 